\title{
An Interdisciplinary Approach to the Electrochemistry at Solid Electrodes
}

\author{
A.J. Arvia, and R.C. Salvarezza \\ Instituto de Investigaciones Fisicoquímicas Teóricas y Aplicadas (INIFTA). Sucursal 4, \\ Casilla de Correo 16, 1900 La Plata, Argentina
}

Received: October 15, 1996

\begin{abstract}
Um enfoque interdisciplinar na eletroquímica em eletrodos sólidos é apresentado levando-se em conta novas interpretações básicas, tanto para o crescimento de fases quanto para a perturbação de fases sob condições longe do equilíbrio. Para esse propósito, os dados de imagens derivadas de microscopia de tunelamento por varredura (STM) e de microscopia de força atômica (ATM) em diferentes escalas de comprimento, se tornam extremamente úteis. Esse enfoque proporciona novas visões no desenvolvimento de rugosidade, decaimento de rugosidade e reatividade em eletrodos sólidos. O estudo de interfaces móveis por aplicação sequencial de dados de STM in situ e a interpretação baseada na teoria da escala dinâmica fornece uma descrição qualitativa e quantitativa das irregularidades da superfície, e provê informações sobre o mecanismo de evolução da interface sob regimes estacionários e não-estacionários de rugosidade. Vários exemplos de interesse eletroquímico são discutidos na base deste enfoque interdisciplinar.
\end{abstract}

An interdisciplinary approach to the electrochemistry at solid electrodes is presented here taking into account new basic interpretations for either phase growth or phase disruption under conditions far from equilibrium. For this purpose imaging data derived from scanning tunneling microscopy (STM) and atomic force microscopy (AFM) at different scale lengths are extremely useful. This approach provides new insights into roughness development, roughness decay and reactivity at solid electrodes. The study of mobile interfaces by the sequential application of in situ STM data and an interpretation based on the dynamic scaling theory furnish a qualitative and a quantitative description of surface irregularities, and provide information about the interface evolution mechanism under steady and non-steady roughness regimes. Various examples of electrochemical interest are discussed on the basis of this interdisciplinary approach.

Keywords: irregular electrode surfaces, nanoscopies, dynamic scaling

\section{Introduction}

Electrochemical reactions take place in an interfacial region comprised between the electrode surface and the bulk of the electrolyte solution. The thickness of the interfacial region extends from the cross section of the adsorbed molecule on the electrode up to the liquid film adjacent to the electrode surface whose composition, generally, differs from that of the solution $^{1-2}$. Within the interfacial region different zones related to some dominant aspects such as the adsorbate layer, the double layer thickness, the concentration gradient of reacting species, and the hydrodynamic profile can be distinguished (Fig. 1). In this context, the simplest approach to such a description results from a liquid metal electrode immersed in a conducting solution. Therefore, for many years electrochemistry focused on the $\mathrm{Hg}$ (liquid)/aqueous dissolution interface to neutralize the influence of the surface topography on the interface properties, which is unavoidable when dealing with solid electrode/solution interfaces. However, less attention has been paid to the effect of the electrode topography on those electrochemical reactions involving solid electrodes, despite the large number of processes in which this type of electrode is employed. 


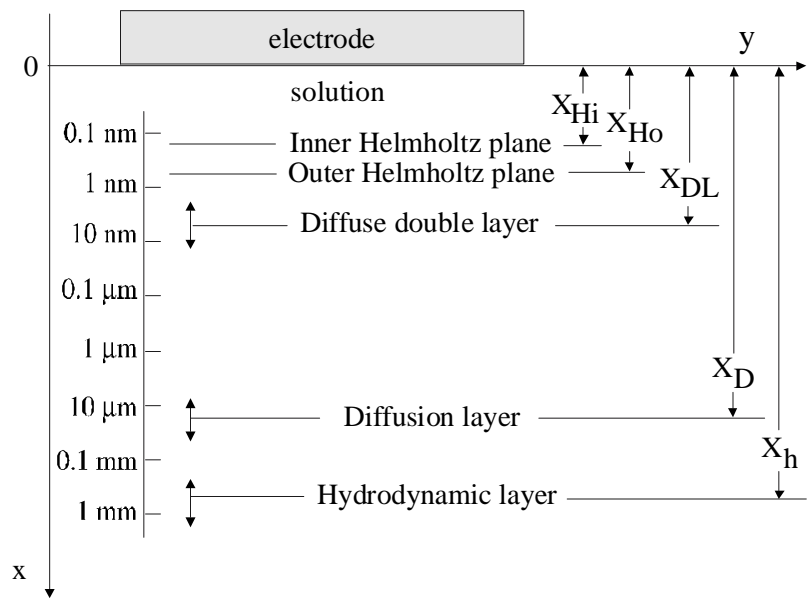

Figure 1. Scheme of the different distinguishable thicknesses (x) related to the solid electrode/solution interface. Distances are estimated for a rotating disc electrode at approximately $100 \mathrm{rpm}$.

Solid electrode surfaces are usually of a complicated nature. In fact, well-defined solid domains are generally restricted to very small surface areas, as can be seen by nanoscopy techniques ${ }^{3}$. Most generally, solid surfaces always exhibit irregularities at different scale lengths ${ }^{4}$.

The problem of surface irregularities always appears in electrochemistry when a new solid phase is formed, as in the case of metal electrodeposition or when a phase is destroyed, as in metal corrosion. The same situation arises in dealing with heterogeneous catalysis and electrocatalysis concerning real surface area measurement and surface reactivity, two important aspects related to the specific efficiency of the catalyst. Therefore, knowledge of the topography and surface structure of the solid down to the atomic level is essential in many aspects, such as predicting its behavior under different operating conditions, and calculating the energetics of possible adsorbate structures in relation to the likely reaction pathways ${ }^{5-6}$. All these aspects are of great importance to handling the optimal kinetic conditions for a particular electrochemical reaction. To tackle these complex problems an interdisciplinary approach is required in which frontier aspects of physics, chemistry, mathematics, and modeling techniques converge.

This paper summarizes how to deal with irregularities at solid surfaces, such as those encountered on solid electrode surfaces, and how they can be quali- and quantitatively treated. This implies an interdisciplinary approach to electrochemical problems of basic importance for electrode design and performance, and provides an explanation for electrode behavior which has occasionally been considered "anomalous" from the standpoint of classic electrochemistry.

\section{Interface Motion}

Processes such as the formation of a solid phase by either vapor phase deposition ${ }^{7}$, epitaxial growth induced by molecular rays ${ }^{8}$, or the growth of metal electrodeposits ${ }^{9}$, and the dissolution of a solid phase as it occurs in corrosion in general ${ }^{10}$, involve an interface motion. The way in which the interface displacement occurs reflects the type of kinetics obeyed by the system and the dominant mechanism operating in the process. In fact, the interface motion can be described by the same tools which are usually employed for other seemingly different processes such as liquid flow through porous media, the propagation of a flame front, the growth of bacterial colonies, or the rupture of a dielectric ${ }^{11}$. The common feature among all of these phenomena is the existence of an irregular mobile interface. For such an interface the challenge is to establish the mechanism of its formation, as well as its dynamic characteristics $^{11,12}$. The evaluation of these characteristics becomes relevant to determine the stability of the mobile interface at either a solid/liquid or a solid/gas interface by using procedures which lead to a minor perturbation in the system and can be applied irrespective of its nature.

\section{Growth Modes}

The growth of a solid phase implies a positive shift of the average interface plane along the z-axis (Fig. 2), whereas the opposite displacement accounts for the phase destruction. In both cases, however, the overall phenomenon can be investigated using the same formalism.

Classical growth models for a solid phase are based upon the existence of local equilibrium on the surface and further admit that the mass transport parallel to the microscopic surface is much faster than the flux of particles arriving at the surface. Within this thermodynamic framework several models have been proposed (Fig. 3). Thus, the Volmer-Weber model $(1926)^{13}$ considers an initial nucleation and tridimensional (3d) growth of the new phase, where d denotes the topological dimension of the object. The Stranski-Krastanov model $(1938)^{14}$ takes into account the formation of an initial layer

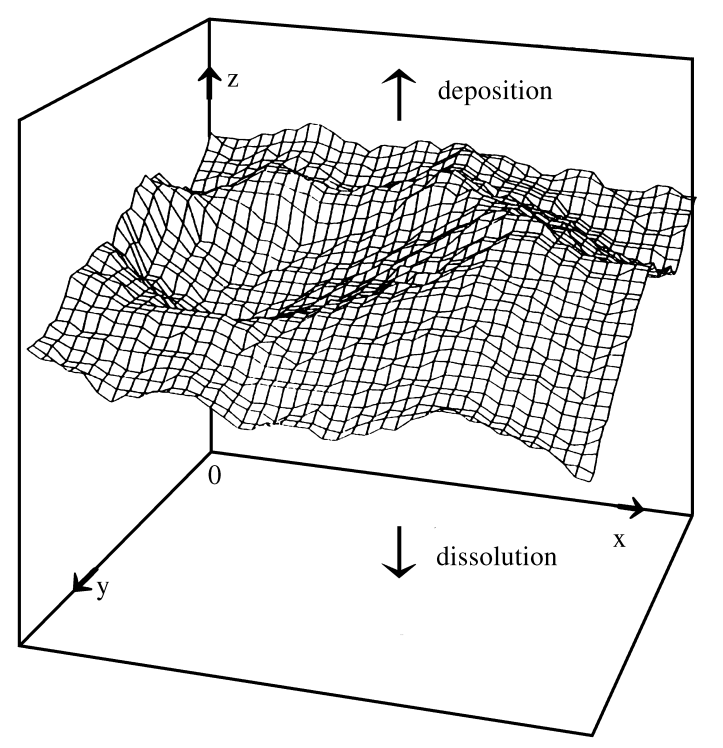

Figure 2. Scheme of the mobile interface. Arrows indicate the interface motion for a deposition at a solid substrate and a solid dissolutionprocess 


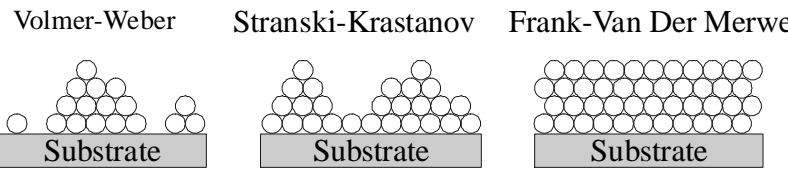

Figure 3. Schemes of phase growth mechanisms based on thermodynamics.

followed by 3d-growth. The Frank-van der Merwe model (1949) ${ }^{15}$ considers layer-by-layer growth.

The above mentioned models have been extensively used in the interpretation of solid phase growth data, despite the fact that in a number of electrochemical examples processes take place far from conditions of equilibrium. Atomic force microscopy (AFM) images of $\mathrm{Cu}$ films produced under potentiostatic conditions at a cathodic overvoltage such as $\eta_{c}$ $=0.149 \mathrm{~V}^{16}$ have shown a remarkable change in the topography during growth, which results in a substantial increase in surface roughness. These facts reflect in the shape of the corresponding current transient itself. In principle, the value of the applied potential, which is far from the equilibrium potential, and the relatively high flux of copper ions arriving at the surface make it somewhat unlikely that under these circumstances thermodynamic models could be applied. Therefore, to answer the question as to whether the shape of the mobile interface could be related to the kinetics of the physical, chemical or electrochemical process, an approach based upon non-equilibrium conditions has to be considered ${ }^{17}$.

A simple experiment to emphasize the main concepts involved in the development of a mobile interface consists of pouring a particulate material onto a solid plane surface (Fig. 4). Initially, the material forms a small heap which increases both in height, at the velocity $\mathrm{v} \uparrow$, and in width, at the velocity $\mathrm{v} \rightarrow$. Accordingly, depending on the $\mathrm{v} \uparrow / \mathrm{v} \rightarrow$ ratio, two limiting situations in the growth mode of the heap can be distinguished. Thus, for $\mathrm{v} \uparrow>\mathrm{v} \rightarrow$, a column tends to be formed, whereas for $\mathrm{v} \uparrow<\mathrm{v} \rightarrow$, a plane is approached. It should be noted that the velocity concept which is involved in this experiment can be easily generalized to a chemical or physical process involving atoms or molecules. However, it should be emphasized that depending on the yardstick used to follow the interface characteristics, the interface can be described às either a discontinuous or a discrete structure. Accordingly, when the yardstick size exceeds the size of particles involved in the interface motion the structure of the interface can be analyzed in terms of continuous growth modes, whereas atomistic models become more adequate to describe discrete interfaces.

\section{The Concept of Scaling. Models far from Equilibrium}

The concept of scaling was introduced in the study of mobile interfaces by Family and Vicsek $(1985)^{18}$ for the analysis of the topography of surfaces under non-equilibrium condi-

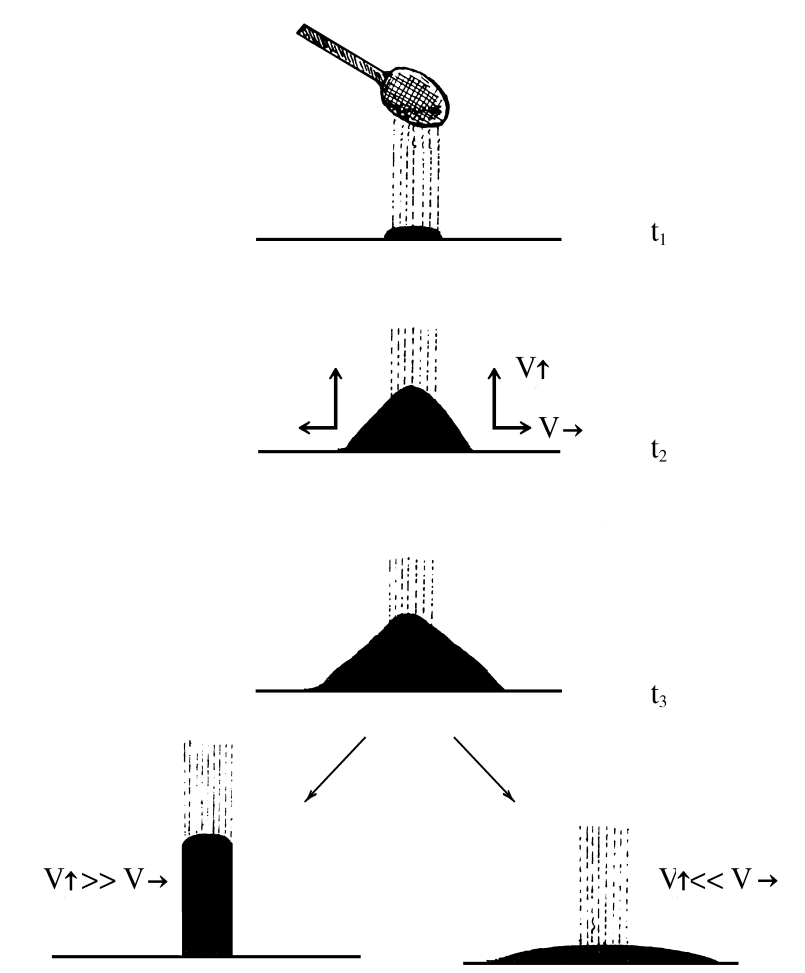

Figure 4. Scheme to illustrate how a heap of a particulate material is formed by pouring it on a flat table. Dashed lines indicate the flux of particles. The shapes of the growing heap at times $t_{1}, t_{2}$ and $t_{3}$ are shown. Heap growth velocity components parallel and perpendicular to the table plane are included. At the bottom, two limiting growth modes leading to a column and to a flat object are depicted.

tions. In dealing with continuous models the application of scaling concepts can be made directly.

The evolution of the irregular interface in continuous models is essentially represented by two types of competitive contributions, one related to the increase in roughness and the other involving surface smoothing ${ }^{11}$. The contribution to the increase in surface roughness is attributed to either the stochastic noise of arriving particles which are incorporated into the new phase or to the random nature of the dissolution process itself. Otherwise, surface smoothing results from the contribution of different relaxation processes among which the surface diffusion of impinging particles in contact with the surface is included. Continuous models for growth of new phases have been developed either for homo- or heterodeposits, and among these models from Edward-Wilkinson $^{19}$, Kardar, Parisi and Zhang model $(1986)^{20}$, Wolf and Villain model $(1990)^{21}$, and Villain, Lai and Das Sarma model (1991) ${ }^{22}$ are the most extensively used.

\section{A Brief Description of the Dynamic Scaling Theory}

According to the dynamic scaling theory the discrete characteristics of the deposited material lead to the irregular interface and explain its fractal behavior. 
Considering an object of length $\mathrm{L}$ at time $\mathrm{t}$, the theory predicts that the interface width, $\mathrm{W}_{\mathrm{L}}(\mathrm{t})$, i.e. the standard deviation of the interface height (Fig. 5), given by:

$$
\mathrm{W}(L, t)=\left(\frac{1}{N} \sum\left[h\left(x_{i}\right)-<h>\right]^{2}\right)^{1 / 2}
$$

obeys the following equation ${ }^{18}$

$$
\mathrm{W}^{2} \mathrm{~L}(\mathrm{t})=\mathrm{L}^{2} \alpha \mathrm{f}\left(\mathrm{t} / \mathrm{L}^{\mathrm{z}}\right)
$$

where, $h\left(x_{i}\right)$ is the deposit height measured along the $\mathrm{x}$-direction at point $\mathrm{x}_{\mathrm{i}},\langle\mathrm{h}\rangle$ is the average height, $\mathrm{f}$ is a function of $\mathrm{t} / \mathrm{L}^{\mathrm{z}}, \alpha$ and $\mathrm{z}$ are the roughness exponents, and $\mathrm{z}$ represents the scaling law.

For small values of $\mathrm{L}$ and constant t, Eq. 2 results in

$$
\mathrm{W}^{2}{ }_{\mathrm{L}}=\mathrm{L}^{2 \alpha}
$$

This equation represents the steady roughness regime which is attained when the condition $t>t_{x}$ is fulfilled. On the

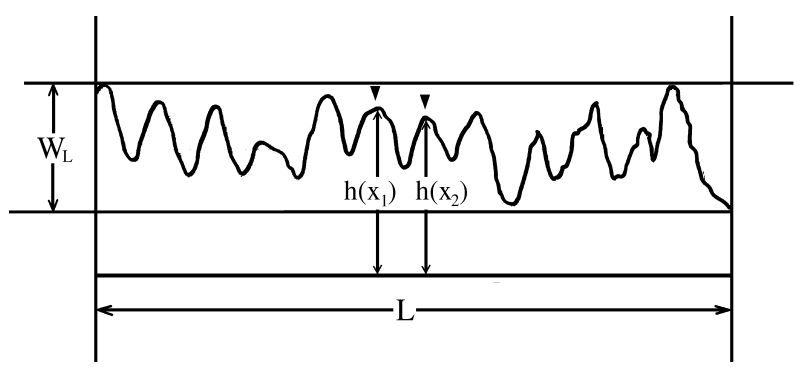

Figure 5. A definition of the terms used in the dynamic scaling analysis of a topographic profile at time t. Profile heights at positions $\mathrm{x}_{1}$ and $\mathrm{x}_{2}$ are indicated. other hand, for $\mathrm{L} \otimes \diamond$ the following relationship is obtained from Eq. 2:

$$
\mathrm{W}^{2} \mathrm{~L}(\mathrm{t})=\mathrm{t}^{2 \beta}
$$

Equation 4 represents the non-steady roughness regime which is found when $t<t_{x}$, with $t_{x}$ being a transition from the non-steady to the steady roughness regime. Exponent $\beta$ is the roughness growth exponent, and $\alpha$ and $\beta$ are related by the ratio $\mathrm{z}=\alpha / \beta$. The physical meaning of exponents $\alpha$ and $\beta$, as well as the non-steady and steady roughness regimes, are illustrated in Fig. 6. In this figure the surface profile for roughness decay is also included. The evaluation of these parameters provides a way to determine the primary mechanism involved in the growth of an irregular interface ${ }^{18}$.

\section{Parameters $\alpha$ and $\beta$ Predicted for Equilibrium Models}

It is interesting to consider the limitations of classical equilibrium growth models for those processes in which a mobile interface if produced far from equilibrium. Thus, for the growth mechanism involved in the Frank-van der Merwe model the dynamic scaling theory predicts $\alpha=\beta=0$, i.e., the surface remains smooth during the growth process ${ }^{23}$.

Similarly, for the mechanism involved in the Stranski-Krastanov and the Volmer-Weber models, the dynamic scaling theory results in values of $\alpha$ in the range $0.5 \leq \alpha$ $\leq 0.6$. For these models, $3 \mathrm{~d}$ islands are formed, the shape of these islands being determined by the energy of growing facets, interface and substrate. In addition, the coalescence of islands means that the solid phase has changed from a

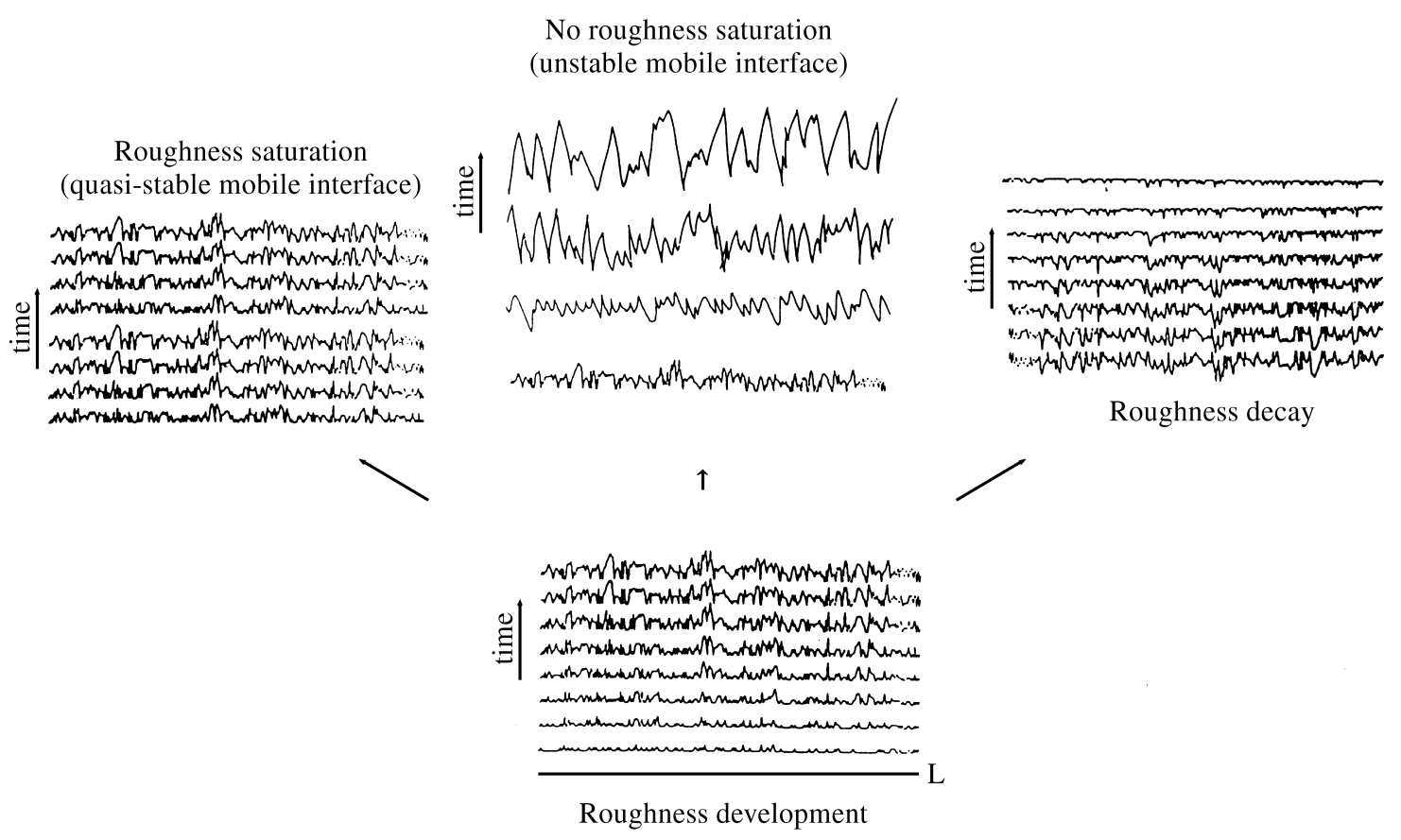

Figure 6. Schemes of profiles for roughness development under different regimes. 
heterogeneous to a homogeneous one $\mathrm{e}^{23}$. All these facts lead to time-dependent values of $\beta$.

\section{Parameters $\alpha, \beta$ and $\mathrm{z}$ and Models far from Equilibrium}

\section{Discrete models}

The ballistic deposition model ${ }^{24}$ implies that every particle arriving at the surfaces sticks at the first contact site (Figs. $7 \mathrm{a}, \mathrm{b})$. The Monte Carlo simulation of this process indicates the existence of an L-dependent correlation along the surface because of the finite particle size. Therefore, $\alpha, \beta$, and $\mathrm{z}$ strongly depend on $L$, but $L \rightarrow \infty$, it results in $\alpha=0.33$ and $\beta=0.25$ for a $3 \mathrm{~d}$ process.

The random deposition model ${ }^{11}$ (Figs. 8a,b) assumes that particles stick at the first deepest site encountered in the particle displacement direction. The attaching mechanism involved is this model leads to a non-steady roughness regime in which the value of $W_{L}$ increases linearly with $t^{1 / 2}$. Accordingly, the value $\beta=1 / 2$ is obtained irrespective of the topographic dimension.

When a surface relaxation term by surface diffusion is included in the random deposition model ${ }^{21}$, which implies the possibility that the particle will shift a distance of 1 on the surface to increase its coordination number (Figs. 9a,b), it results in $\alpha=1$ and $\beta=0.25$ in $3 \mathrm{~d}$. When full surface diffusion is allowed $\alpha=0$ and $\beta=0$ in $3 \mathrm{~d}$ are obtained ${ }^{19}$.

\section{Continuous models}

Continuous models for interface motion are based upon the Langevin equation ${ }^{25}$. This equation establishes that for an
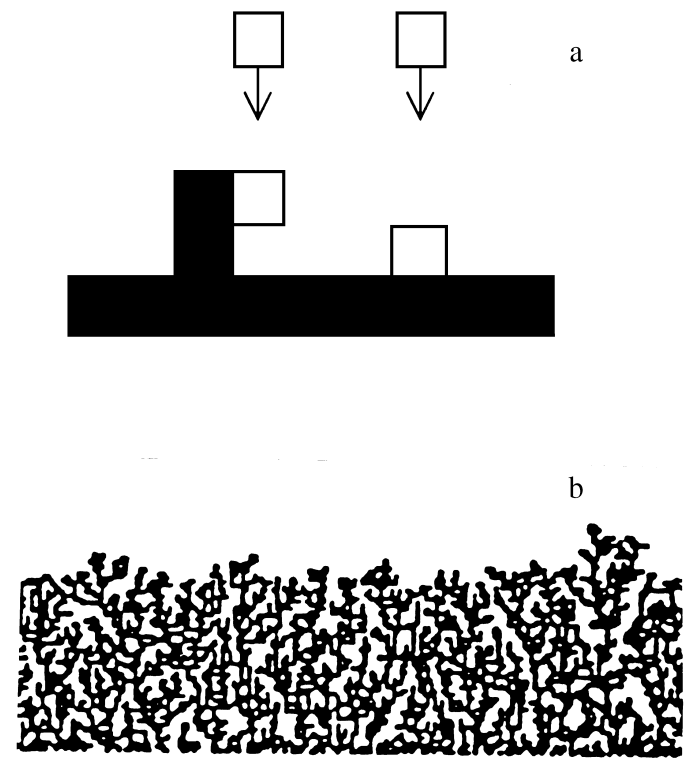

Figure 7. Schemes showing the motion of attaching particles (a) and resulting profile (b) for a phase growth according to the ballistic deposition model. irregular interface the local rate for the height increase, $\mathrm{h}(\mathrm{x})$, is given by

$$
\frac{\partial h(x, t)}{\partial t}=v \nabla^{2} h
$$

The solution of Eq. 5 only corresponds to a non-steady roughness regime with $\beta=0.50$. The coefficient $v$ is the so-called surface tension term.

Based on Eq. 5, the Edwards and Wilkinson ${ }^{19}$ equation includes a smoothing term, $\eta(\mathrm{x}, \mathrm{t})$, which comes from the stochastic noise of finite arriving particles. Then,

$$
\frac{\partial h(x, t)}{\partial t}=v \nabla^{2} h+\eta(x, t)
$$

By solving Eq. 6 for $\mathrm{d}=3$, the set of exponents obtained is $\alpha=0$ and $\beta=0$, i.e. they are equivalent to the random deposition with the full surface diffusion atomistic models.

A further improvement was made by Kardar, Parisi and Zhang (KPZ) ${ }^{20}$ by adding a non-lineal term to Eq. 6 to account for lateral effects in the interface growth. Then, the KPZ interface motion equation results in

$$
\frac{\partial h(x, t)}{\partial t}=v \nabla^{2} h+\frac{\lambda}{2}(\nabla h)^{2}+\eta(x, t)
$$
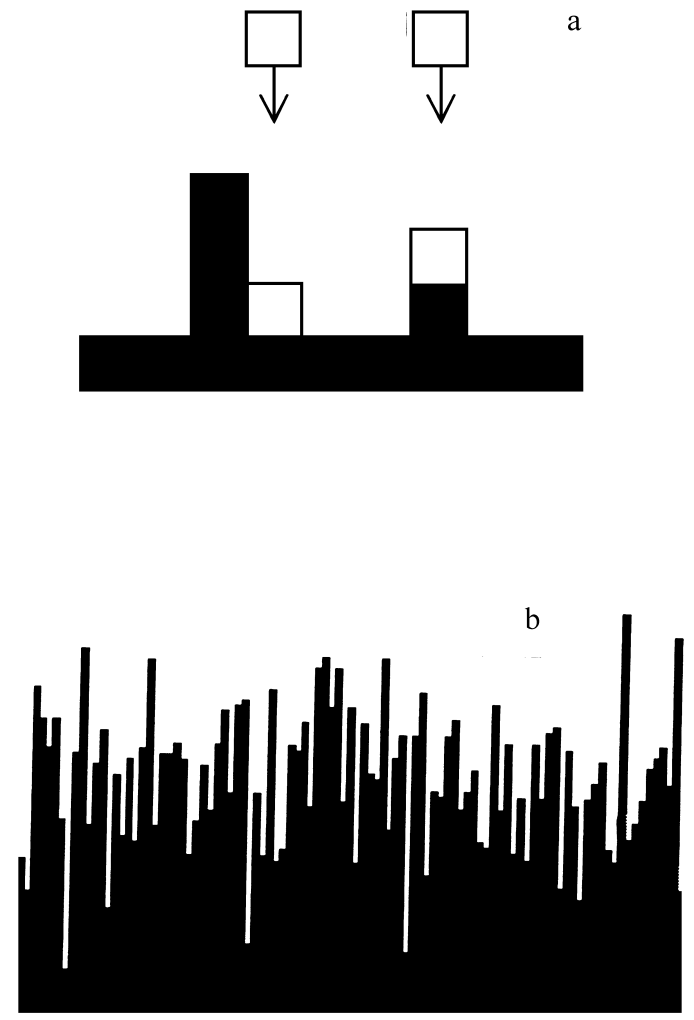

Figure 8. Schemes showing the motion of attaching particles (a) and resulting profile (b) for a phase growth according to the random deposition model. 

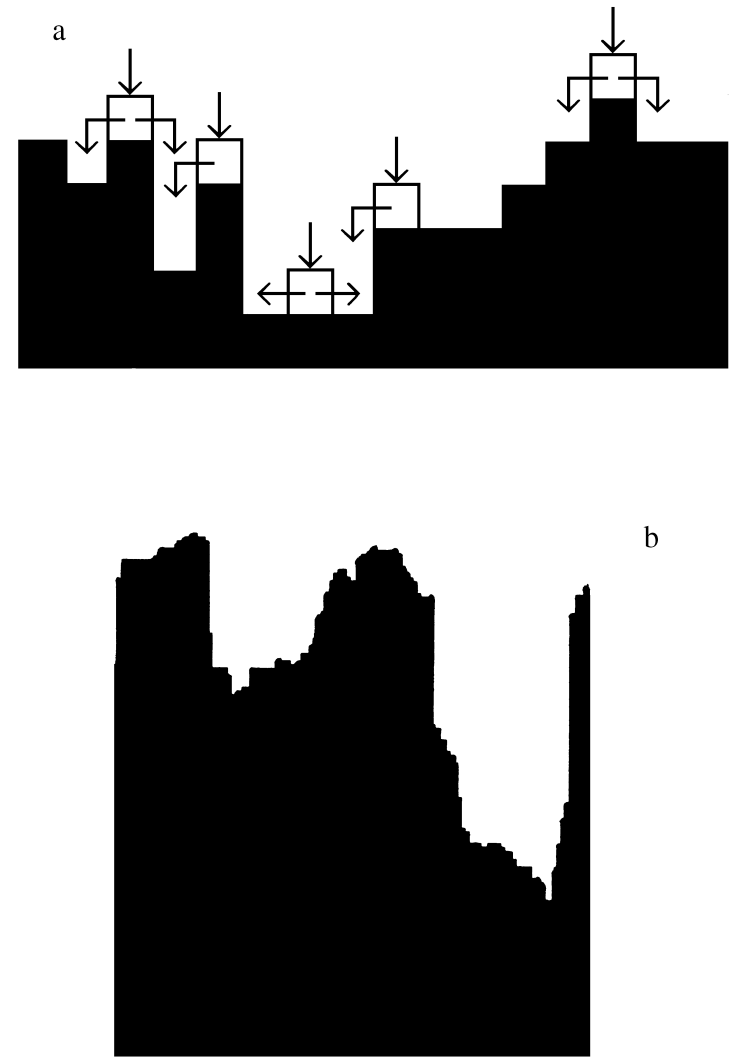

$\mathrm{b}$

Figure 9. Schemes showing the motion of attaching particles (a) and resulting profile (b) for a phase growth according to the random deposition with surface relaxation model.

For $\mathrm{d}=3$, Eq. 7 predicts $\alpha \cong 0.38$ and $\beta \cong 0.25^{11}$. Thus, this equation accounts for the ballistic deposition and the atomistic growth models ${ }^{26}$.

Wolf and Villain ${ }^{21}$ propose a linear model in which smoothing is exclusively produced by surface diffusion. The corresponding interface motion equation is given by

$$
\frac{\partial h(x, t)}{\partial t}=\nu \nabla{ }^{4} h+\eta(x, t)
$$

The first term into Eq. 8 leads to a non-steady roughness regime as it corresponds to Fick's law for diffusion, whereas the second term operates in an opposite way. The solution from Eq. 8 for $3 \mathrm{~d}$ yields $\alpha=1$ and $\beta=1 / 4$.

Finally, a further improvement was made by Lai and Das Sarma whose model incorporates a lateral interaction term to Eq. $8^{22}$,

$$
\frac{\partial h(x, t)}{\partial t}=\nu \nabla^{2} h+\lambda \nabla^{2}(\nabla h)^{2}+\eta(x, t)
$$

At the early stages of growth the solution of Eq. 9 for $3 d$ furnishes $\alpha=1$ and $\beta=1 / 4$, whereas for $\mathrm{t} \otimes \diamond$, the exponents are $\alpha=2 / 3$ and $\beta=1 / 5$.

In sum, knowledge of the dynamic scaling parameters offers a sensitive and conclusive way to determine the prevailing mechanism in the growth mode of a new phase under conditions far from equilibrium, through the evolution of the interface. The application of the dynamic scaling theory to nanoscopy imaging data becomes possible because of their real space characteristics and their wide scaling range.

\section{Examples of the Application of the Dynamic Scaling Theory to Electrochemical Systems}

The development of the roughness theory was accompanied by advances in the development of nanoscopy, such as scanning tunneling microscopy (STM), atomic force microscopy (AFM) and other microscopies derived from STM and AFM. The availability of these techniques allows us to obtain the real topography of a solid in contact with any environment from the atomic scale upward. The following examples describe the application of the dynamic scaling theory to real situations.

This approach allowed us to discover new kinetic contributions to electrochemical reactions, to confirm others which had been indirectly concluded from electrochemical kinetic studies, and to explain "anomalous" facts. The wide variety of experimental data gathered in recent years constituted good support for testing the validity of theoretical approaches and envisaging new ways to improve the modeling of the interface motion.

Non-stationary and stationary roughness regimes.

Silver electrodissolution in aqueous acid solution

Metal electrodissolution in aggressive aqueous electrolyte media implies the separation of particles from the solid phase and the creation of vacancies. The overall process is accompanied by the development of an irregular interphase. A typical example of this process is the electrodissolution of a $\mathrm{Ag}$ single crystal domain in $0.1 \mathrm{M} \mathrm{HClO}_{4}$ at $25^{\circ} \mathrm{C}^{10}$. This specimen was subjected to a galvanostatic electrooxidation at either $\mathrm{j}<15$ $\mu \mathrm{A} \mathrm{cm}^{-2}$ or $\mathrm{j}>15 \mu \mathrm{A} \mathrm{cm}^{-2}$, and the amount of electrodissolved $\mathrm{Ag}$ in both cases was equivalent to approximately 150 monolayers.

For $\mathrm{j}<15 \mu \mathrm{A} \mathrm{cm}^{-2}$, the silver surface shows no changes in roughness (Fig. 10a) as opposed to the result obtained for $\mathrm{j}>15 \mu \mathrm{A} \mathrm{cm}^{-2}$ (Fig. 10b). In the latter case, the $\left(\mathrm{W}_{\mathrm{L}}\right)_{\text {sTM }} v s . \mathrm{t}$ plot shows the appearance of non-steady and steady roughness growth during electrodissolution (Fig. 10c). This fact makes it possible to evaluate $\alpha$ and $\beta$ following the above-mentioned procedures, resulting in $\alpha=0.90$ and $\beta=0.36$. The value of $\alpha$ is close to that expected for the Villain-Wolf model ${ }^{21}$ although the value $\beta=0.36$ exceeds the expected $\beta=0.25$. However, when surface diffusion is restricted to the terrace surfaces due to the presence of energy barriers at step edges, the value of $\beta$ changes from 0.25 to 0.40 as the interlayer mass transport is progressively hindered without any changes in the value of $\alpha$. Therefore, the values $\alpha=0.90$ and $\beta=0.36$ indicate that for $\mathrm{Ag}$ electrodissolution at $\mathrm{j}>15 \mu \mathrm{A} \mathrm{cm}^{-2}$, there is a strong contribu- 


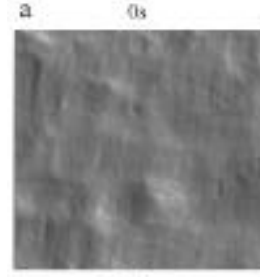

$4752 \mathrm{~s}$

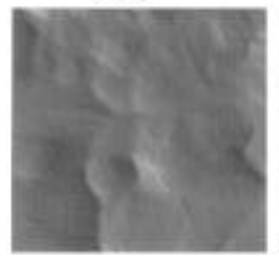

Dos

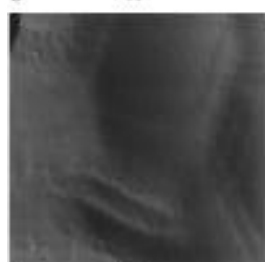

$355 \mathrm{~s}$

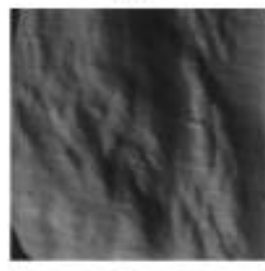

7018
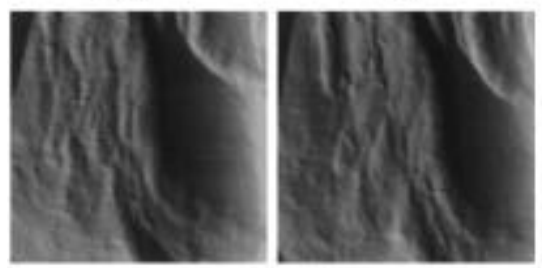

400

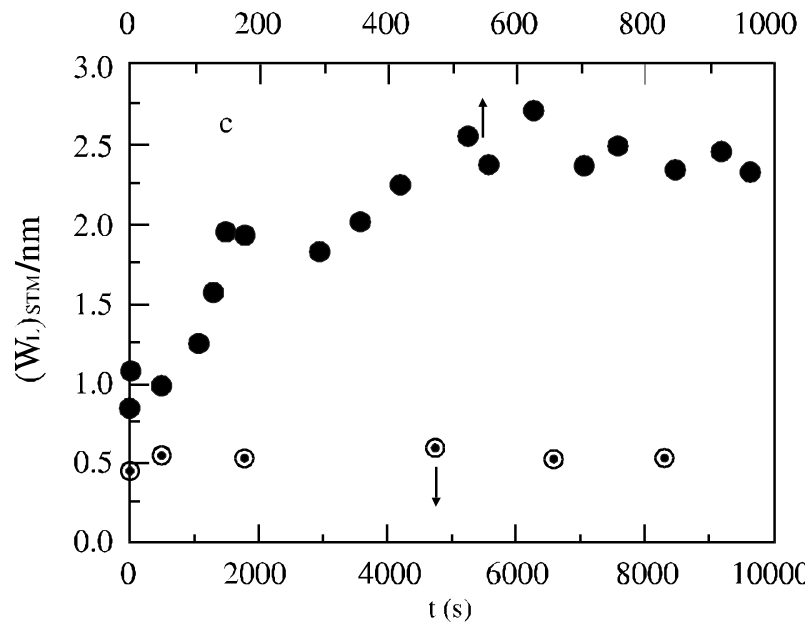

Figure 10. In situ STM images of silver electrode surfaces immersed in $1 \mathrm{M} \mathrm{HClO}_{4}$ at $\mathrm{j}=4 \mu \mathrm{A} \mathrm{cm}^{-2}$ (a) and $\mathrm{j}=30 \mu \mathrm{A} \mathrm{cm}^{-2}$; (b). T $=298 \mathrm{~K}$; (c) $\left(\mathrm{W}_{\mathrm{L}}\right) v s . \mathrm{t}$ plot; $(\bullet) \mathrm{j}=30 \mu \mathrm{A} \mathrm{cm}^{-2}(\mathrm{O}) \mathrm{j}=4 \mu \mathrm{A} \mathrm{cm} \mathrm{cm}^{-2}$. tion of surface atom diffusion with restricted interlayer mass transport. Such a situation implies that a Schwoebel energy barrier is located at the steps ${ }^{27}$.

This result confirms previous conclusions derived from electrochemical kinetic data on silver electrodes establishing that surface diffusion processes play a key role in the kinetics of the silver electrode.

A non-stationary roughness regime.

The electrodissolution of $\mathrm{Cu}$ in acid solutions

Experiments similar to those described above for $\mathrm{Ag}$ electrodissolution were made for $\mathrm{Cu}$ in the same solutions, starting from a $\mathrm{Cu}$ single crystal domain ${ }^{28}$ with characteristics similar to those reported for Ag.

Under open circuit conditions the electrode surface becomes considerably mobile, showing a trendency to decrease in roughness due to the disappearance of the small pits initially present on the surface.

The above described situation becomes even more complex for $\mathrm{j}=6 \mu \mathrm{A} / \mathrm{cm}^{-2}$, since in this case a clear nonhomogeneous attack of the $\mathrm{Cu}$ surface can be observed yielding domains with a faceted topography, domains with a relatively low increase in roughness, and domains where deep etched pits are formed (Fig. 11a). The formation of etched pits can be seen after a relatively long dissolution time.

The dynamic scaling analysis applied to the first and second type of attack at the early stages of the process, leads to a behavior which is similar to that already described for $\mathrm{Ag}$. In contrast, the overall attack of $\mathrm{Cu}$ leads to a non-steady roughness regime, as can be seen from the $\left(\mathrm{W}_{\mathrm{L}}\right)_{\text {STM }} v s$. t plot (Fig. $11 b)$ which exhibits a continuously increasing slope. Therefore, from the dynamic scaling analysis of scanning force microscopy imaging only the value of $\beta$ can be estimated from the $\log \left(\mathrm{W}_{\mathrm{L}}\right)_{\mathrm{STM}} v s . \log \mathrm{L}$ plot for this system.

For those domains where etched pits are absent, $\beta=0.36$. This value indicates the crucial role played by $\mathrm{Cu}$ atom surface diffusion in the early stages of $\mathrm{Cu}$ electrodissolution, but the value $\beta>0.25$ suggests that surface diffusion also involves, as in the case of Ag electrodissolution, a Schwoebel type of energy barrier at the steps. Surface diffusion in this case is probably anisotropic, a fact which may explain the directional faceting produced at certain domains of the $\mathrm{Cu}$ surface in the process.

On the other hand, the value of $\beta>1$ resulting from the overall electrodissolution indicates a global process dominated by the formation of etched pits. This result is particularly relevant, as it may throw light on the possible origin of pitting corrosion of metals. It also emphasizes the difficulty in interpreting conventional Tafel plots for metal electrodissolution when the real surface area becomes uncertain.

The evaluation of $z$ through roughness decay imaging data. Columnar-structured gold electrodes 
The contribution of surface atom diffusion to post-deposition surface roughness evolution was studied for columnar-structured Au films on Au. These surfaces were prepared from the electroreduction of thick hydrous Au oxides accumulated on Au by anodization at $2.6 \mathrm{~V}$ (vs. standard hydrogen electrode, $\mathrm{SHE}$ ) in $0.5 \mathrm{M} \mathrm{H}_{2} \mathrm{SO}_{4}$. This procedure results in the formation of nanometer Au particles (Fig. 12a, $\mathrm{t}=$ 0 ) which coalesce in time yielding large particles when aged in $0.5 \mathrm{M} \mathrm{H}_{2} \mathrm{SO}_{4}+0.1 \mathrm{M} \mathrm{NaCl}$ (Fig. 12a) ${ }^{29}$.

From the STM images the average radius of growing particles in the $\mathrm{x}$-direction $\left(\mathrm{r}_{\mathrm{x}}\right)$ can be obtained for the coarsening process. Data fit a $r_{x} \sim t^{1 / 4}$ plot (Fig. 12b), as is expected for the case in which the surface diffusion of atoms plays a dominant role in the kinetics of coarsening. This type of relationship has been previously expressed by Ostwald's ripening law of colloids.

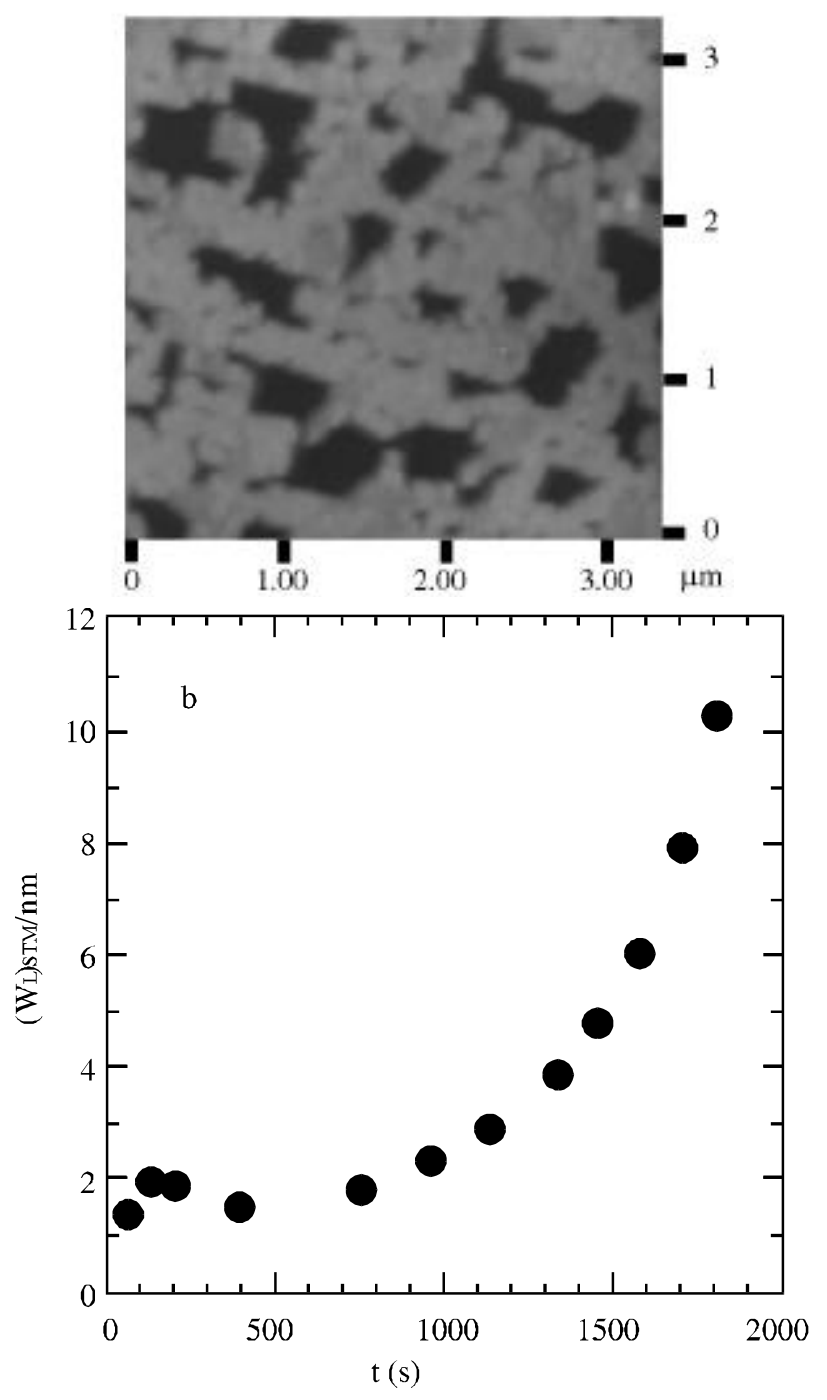

Figure 11. (a) A STM image of a copper electrode surface immersed in $1 \mathrm{M} \mathrm{HClO}_{4}$ at $\mathrm{j}=6 \mu \mathrm{A} \mathrm{cm}^{-2}$; (b). ( $\left.\mathrm{W}_{\mathrm{L}}\right) v s$. t plot; $\mathrm{j}=6 \mu \mathrm{A} \mathrm{cm}$; $\mathrm{T}=298 \mathrm{~K}$.

\section{The Kinetic Consequences of Surface Fractality. The Enhancement of $\mathbf{H}$-atom Electroadsorption on Pd Electrodes}

When a Pd oxide layer produced in an acid solution by the potential reversal technique using $\mathrm{E}_{\mathrm{u}}=1.7(\mathrm{SHE}), \mathrm{E}_{\mathrm{l}}=0 \mathrm{~V} ; \mathrm{f}=$ $1 \mathrm{kHz}, \tau_{\mathrm{u}} / \tau_{1}=9$ and $\mathrm{t}_{\mathrm{prt}}=3 \mathrm{~min}$ is electroreduced at a constant potential or with an adequate potentiodynamic sweep, it results in a Pd layer which exhibits an enhancement for the $\mathrm{H}$-atom electrosorption process as revealed by conventional

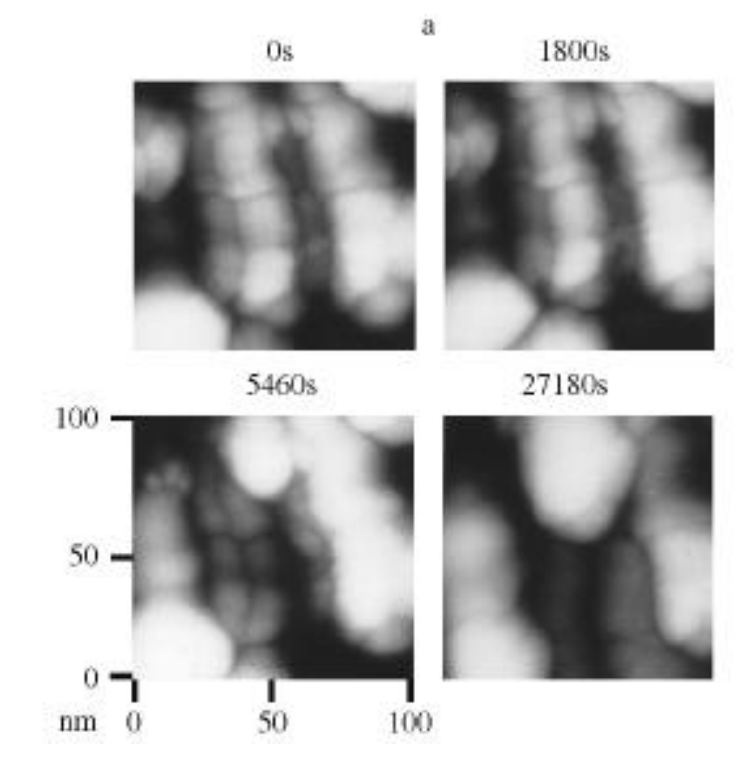

a $1800 \mathrm{~s}$

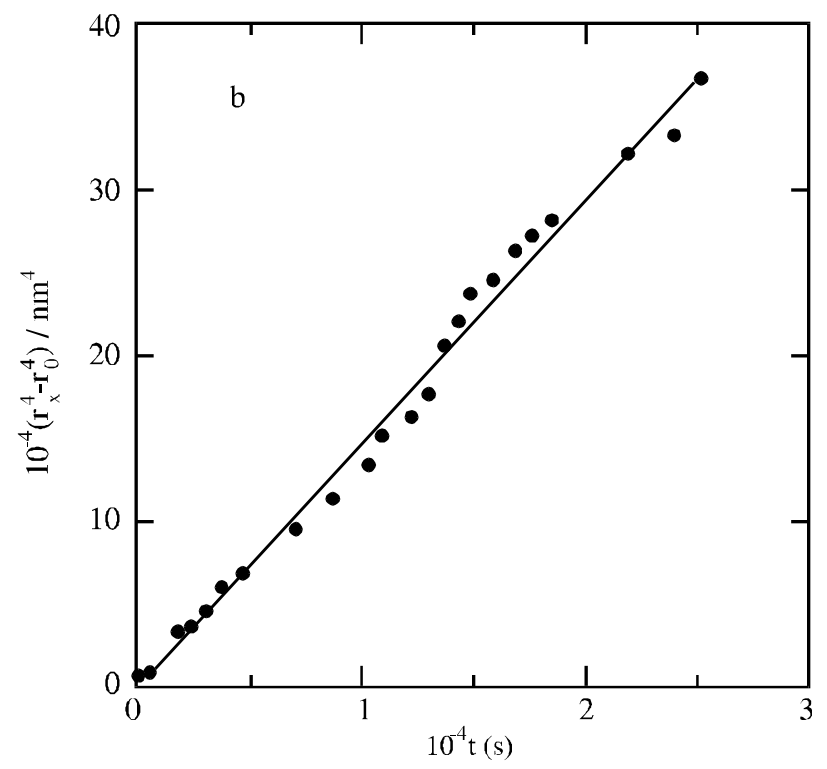

Figure 12. (a) Sequential in situ STM images of a columnar-structured gold electrode surface immersed in $0.5 \mathrm{M} \mathrm{H}_{2} \mathrm{SO}_{4}+$ $0.1 \mathrm{M} \mathrm{NaCl} ; \mathrm{E}=0.6 \mathrm{~V}$ (vs. SHE). (b).Plot corresponding to the change in the particle radius measured in the $\mathrm{x}$-direction as a function of the immersion time. A correction for the initial radius of the particle is considered. $\mathrm{T}=298 \mathrm{~K}$. 

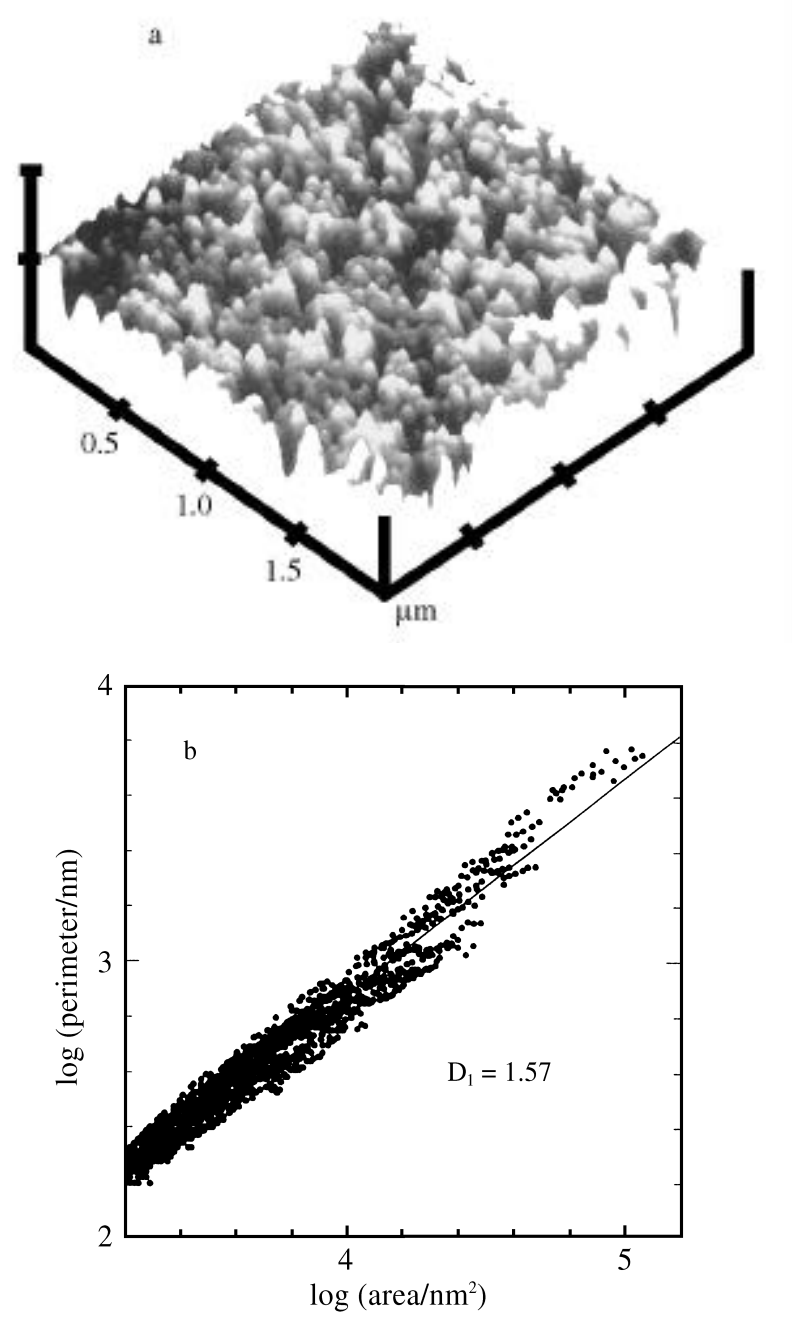

Figure 13. (a) An ex situ AFM image of a columnar structured palladium electrode produced by the electroreduction of a hydrous palladium oxide layer on palladium. (b) Log (perimeter) vs. $\log$ (area) plot to calculate the surface fractal dimension of the electrode surface depicted in (a). The fractal dimension was calculated following the procedure described in the literature ${ }^{31}$.

voltammetry and triangularly modulated triangular potential voltammetry $^{30}$.

To explain this apparently anomalous effect, the palladium surface was investigated using atomic force microscopy (Nanoscope III, Digital) under the contact mode operation. AFM images show an irregular column-like structure (Fig. 13a) which was analyzed following the "lakes and island" procedure described elsewhere to determine $D_{s}$, the fractal dimension of the surface ${ }^{31}$.

Accordingly, the value of $D_{s}=D_{l}+1$, where $D_{l}$ is the fractal dimension of the perimeter of lakes resulting from a $\log$ (perimeter) vs. $\log$ (area) of lakes plot (Fig. 13b). For the Pd surface shown in Fig. 13a, $D_{1}=1.57$ and $D_{s}=2.57$. This means that the surface of Pd is fractal. The physical meaning of a fractal surface is that the atoms which constitute the material tend to occupy the largest surface, and therefore, on this type of surface it is expect that surface processes will prevail over bulk diffusion processes. This explains the particular characteristics of Pd electrodes produced by the above-mentioned procedure, which entails a net enhancement of $\mathrm{H}$-electrosorption processes. It should be noted that for $\mathrm{Pd}$, as observed for Pt columnar fractal surfaces ${ }^{31}$, the roughness decay discussed in the previous section for Au is not relevant due to the surface mobility of $\mathrm{Pd}$ and $\mathrm{Pt}$ which is slower than that of $\mathrm{Au}$. Surface mobility must be considered in dealing with the efficiency of solid catalysts in a number of chemical and electrochemical reactions.

Therefore, the same process may lead to the development of different surfaces, a fact which under adequate control becomes particularly relevant for the design of solid catalysts and electrocatalysts.

\section{Conclusions}

- The dynamic scaling method and fractal geometry are powerful tools for studying interface dynamics and understanding the role of surface irregularities in electrochemical kinetic data.

- Dynamic scaling analysis can be successfully applied to scanning tunneling and scanning atomic nanoscopy imaging data, which represent topographic data in a real space.

- Roughness development involves a non-steady and a steady roughness regime.

- Under a non-steady roughness regime the value of $\beta$ can be estimated.

- When both the non-steady and the steady roughness regimes can be determined, then the value of $\alpha, \beta$ and $z$ can be obtained.

- From the dynamic scaling analysis of roughness decay the value of $\beta$ can be determined.

- From the values of $\alpha, \beta$ and $z$, the kinetics and mechanism of those electrochemical reactions in which an interface motion is involved can be deduced.

- Surface atom diffusion, a contribution which is usually envisaged from electrochemical kinetic data, can be more convincingly demonstrated by the dynamic scaling analysis of STM and SFM imaging data.

- The existence of a fractal surface can explain some experimental data which have often been considered anomalous in terms of the classic models.

\section{Acknowledgments}

This work was financially supported by the Consejo Nacional de Investigaciones Científicas y Técnicas and the Comisión de Investigaciones Científicas de la Provincia de Buenos Aires. 


\section{References}

1.Levich, V. In Physicochemical Hydrodynamics; Prentice-Hall; Englewood Cliffs, 1962.

2. Albery, J. In Electrode Kinetics; Clarendon Press; London, 1975.

3. Behm, R.J. In Scanning Tunnelling Microscopy and Related Methods; Behm, R.J.; García, N.; Rohrer, H.; Eds.; Kluwer; Doordrecht, 1990.

4. Solids far from Equilibrium; Godreche, C. Ed.; Cambridge University Press; Cambridge, 1992.

5. Somorjai, G. I. In Chemistry in Two Dimensions: Surfaces; Cornell University Press; Ithaca, 1981.

6. Gómez, M.M.; García, M.P.; San Fabián, J.; Vázquez, L.; Salvarezza, R.C.; Arvia, A.J. Langmuir 1996, 12, 818.

7. Vázquez, L.; Salvarezza, R.C.; Herrasti, P.; Ocón, P.; Vara, J.M.; Arvia, A.J. Surf. Sci. 1996, 345, 17.

8. Ernst, H.J.; Fabre, F.; Folkerts, R.; Lapujoulade, J. Phys. Rev. Lett. 1994, 72, 112.

9. Vázquez, L.; Salvarezza, R.C.; Herrasti, P.; Ocón, P.; Vara, J.M.; Arvia, A.J. Phys. Rev. B 1995, 52, 2032.

10. Vela, M.E.; Andreasen, G.; Hernández Creus, A.; Salvarezza, R.C.; Arvia, A.J. Phys. Rev. B 1996, 53, 10217.

11. Barabási, A.L.; Stanley, H.E. In Fractal Concepts in Growth Phenomena; Cambridge University Press; Cambridge, 1995.

12. Vicsek, T. In Fractal Growth Phenomena; World Scientific; Singapore, 1989.

13. Volmer, M.; Weber, A. Z. Phys. Chem. 1926, 119, 277.

14. Stranski, J.N.; Krastanov, L. Ber. Akad. Wiss. Wien 1938, 146, 797.

15. Frank, F.C.; van der Merwe, J.H. Proc. Roy. Soc. London A 1949, 198, 205.

16. Rynders, R.M.; Alkire, R.C. J. Electrochem. Soc. 1994, 141, 1166.
17. Salvarezza, R.C.; Arvia, A.J. In Modern Aspects of Electrochemistry; Conway, B.E., Bockris, J.O'M., White, R.E., Eds.; Plenum Press; New York, 1996, Vol. 28, Chap. 5, p. 289.

18. Dynamics of Fractal Surfaces; Family, F., Vicsek, T., Eds.; World Scientific; Singapore, 1991; Family, F.; Physica 1990, 168A, 561, and references therein.

19. Edwards, S.F.; Wilkinson, D.R. Proc. Roy. Soc. London A 1982, 381, 17.

20. Kardar, M.; Parisi, G.; Zhang, Y.C. Phys. Rev. Lett. 1986, 56, 889 .

21. Wolf, D.; Villain, J. Europhys. Lett. 1990, 13, 389.

22. Lai, Z.W.; Das Sarma, S. Phys. Rev. Lett. 1991, 66, 2348.

23. Tong, W.M.; Stanley Williams, R.; Yanase, A.; Segawa Y.; Anderson, M.S. Phys. Rev. Lett. 1994, 72, 3374.

24. Meakin, P.; Ramanlal, P.; Sander, L.M.; Ball, R.C. Phys. Rev. A 1986, 34, 509.

25. Family, F. Physica A 1990, 168, 561.

26. Eden, M. In Proceedings of the 4th Berkeley Symposium on Mathematical Statics and Probability; Neyman, F., Ed.; University of California Press; Berkeley, 1961, Vol. 4.

27. Zhang, Z. Decht, J.; Metiu, H.; Phys. Rev. B 1993, 48, 4972.

28. Aziz, S.G.; Vela, M.E.; Andreasen, G.; Salvarezza, R.C.; Arvia, A.J. Electrochem. Acta, in press.

29. Andreasen, G.; Nazzarro, M.; Ramirez, J.; Salvarezza, R.C.; Arvia, A.J. J. Electrochem. Soc. 1996, 143, 466.

30. Kessler, T.; Visintin, A.; Bolzan, A.E.; Andreasen, G.; Salvarezza, R.C.; Triaca, W.E.; Arvia, A.J. Langmuir 1996, 12, 6587.

31. Gómez-Rodríguez, J.M.; Vázquez, L.; Baró, A.; Salvarezza, R.C.; Vara, J.M.; Arvia, A.J. J. Phys. Chem. 1992, 96, 347. 